\title{
Acute Renal Failure Due to Traumatic Rhabdomyolysis
}

\author{
Pages with reference to book, From 59 To 61 \\ Rubina Naqvi, F. Akhtar, I. Yazdani, S. Hafiz, N. Zafar, A. Naqvi, A. Rizvi ( Sindh Institute of Urology and Transplantation. \\ Dow Medical College, Karachi. )
}

\begin{abstract}
Tratima and non-traumatic insults can cause muscle damage to such an extent that serious sequelae to other organs may result. Myoglobmuna and subsequent acute renal failure (ARF) is a well known and widely studied fact of such sequelae. Twelve cases of ARF (between 1990-1993) who have developed renal dysfunction after prolonged muscular exercise e.g., squat jumping, sit-ups and blunt trauma from sticks or leather belts mainly given by law enforcing personnel for certain issues were studied. None of them had previous history of myopathy, neuropathy or renal disease. All were critically ill on presentation and required renal support in the form of dialysis. Although morbidity was high in all, eleven of them recovered and one expired due to sepsis (JPMA 45:59,1995).
\end{abstract}

\section{Introduction}

The role of traumatic rhabdomyolysis and myoglobinuria in acute renal failure (ARF) was first recognised by Bywaters and Beall during world war II $^{1}$. Since then several aetiological factors both traumatic and non-traumatic have been identified. The main factors causing rhabdomyolysis are alcoholism $^{2}$ direct trauma ${ }^{3}$, chemical intoxication ${ }^{4}$, drug overdosage ${ }^{2}$, exhaustive exercise ${ }^{5}$, seizures ${ }^{4}$, severe infections ${ }^{6}$ and myositis ${ }^{4}$. This paper describes presentation and management of rhabdomyolysis and subsequent ARF caused by blunt trauma where individuals were subjected to repeated beating and torture by blunt objects and/or exhaustive forced exercise.

\section{Patients and Methods}

Between January 1991 and December, 1993 twelve patients were admitted in acute renal failure with history of trauma. Initial work-up included a detailed physical and clinical examination and history of trauma. Complete blood picture, urine analysis, urea, creatinine and electrolytes and ultrasound kidneys were done. The diagnosis of acute renal failure was established on the basis of a history of oliguria/anuria of more than 48 hours and significant rise in serum levels of nitrogenous wastes without any previous history of illness and normal size of kidneys on ultrasound. Specific investigations relevant to rhabdomyolysis included urinalysis for evidence of myoglobin, CPK, LDH. SGOT, calcium and uric acid. The management of these patients included haernodialysis, symptomatic treatment, electrolyte correction and hydration where appropriate.

\section{Results}

Of the twelve patients admitted with acute renal failure, $50 \%$ received blunt trauma, $25 \%$ were subjected to strenuous exercise while the rest $25 \%$ received both. Duration of trauma .ranged from 2 to 12 hours in some cases while in others it lasted on and off for several days with a maximum offive days. All twelve patients were males with a mean age of 27 years and range 18-30 years. The mean days of presentation was 7 days with a range 3-20 days. $25 \%$ of the patients presented early (within 4 days) the rest were all late presentations post-trauma. Seventy-five percent of the patients had bruises, 
$91 \%$ flank pain, $66 \%$ haematuria, $75 \%$ nausea, $66 \%$ vomiting, $50 \%$ haematamesis and majority of the patients were in a normal state of hydration. Routine laboratory findings showed low haemoglobin in $5(41 \%)$ and leucocytosis in $3(25 \%)$ patients. All had acidic urine, occult blood was positive in all but one and all patients had microscopic haematuria. Myoglobin was positive in 3(25\%) patients. Of the 12 patients, 5(41\%) were anunc, 50\% were oligunc and 1 had normal urine output (Table 1).

\begin{tabular}{|c|c|c|c|c|c|c|c|c|}
\hline \multirow{2}{*}{$\begin{array}{l}\text { Patient } \\
\text { No. }\end{array}$} & \multicolumn{2}{|c|}{ Hematology } & \multicolumn{5}{|c|}{ Significant Urinary Findings } & \multirow[b]{2}{*}{$\begin{array}{l}\text { Urine volume } \\
\mathrm{mL} / 24 \text { hours. }\end{array}$} \\
\hline & $\begin{array}{l}\mathrm{Hb} \\
(\mathrm{G} / \mathrm{dl})\end{array}$ & $\begin{array}{l}\text { WBC } \\
\left(\times 10^{\wedge} 9 / 1\right)\end{array}$ & Colour & $\mathrm{pH}$ & Oecult Blood & $\mathrm{RBC} s / \mathrm{HPF}$ & Myoglobin & \\
\hline 1 & $* 8.1$ & 10.4 & Yellow & 5.5 & + & Occasional & $\cdot$ & $<100$ \\
\hline 2 & 13.1 & 10.7 & Brownish red & 6.0 & + & $30-35$ & + & $<500$ \\
\hline 3 & 12.0 & 7.8 & Yellow & 5.5 & Nil & $10-15$ & . & Normal \\
\hline 4 & $\bullet 11.1$ & 18.6 & Brownish red & 6.0 & + & Numerous & + & $<100$ \\
\hline 5 & 12.3 & 9.2 & Brownish red & 5.5 & ++ & Numerous & - & $<100$ \\
\hline 6 & $* 7.3$ & 9.7 & Brownish red & 5.0 & ++ & Numerous & + & $<\$ 00$ \\
\hline 7 & 12.0 & 15.2 & Reddish & 5.5 & + & $40-45$ & - & $<100$ \\
\hline 8 & 16.2 & 10.6 & Yellow & 5.5 & + & $30-35$ & - & $<100$ \\
\hline 9 & $\bullet 9.1$ & 18.1 & Yellow & 6.0 & ++ & $10-15$ & * & $<500$ \\
\hline 10 & 12.7 & 10.4 & Yellow & 5.5 & ++ & $50-60$ & - & $<500$ \\
\hline 11 & 14.3 & 12.0 & Reddish & 5.5 & ++ & $60-65$ & - & $<500$ \\
\hline 12 & $\bullet 10.7$ & 11.8 & Yellow & 5.0 & + & $20-25$ & - & $<500$ \\
\hline
\end{tabular}

Biochemical investigation (Table II)

Table Il. Biochemical Findings at Admission

\begin{tabular}{|c|c|c|c|c|c|c|c|c|}
\hline \multirow{2}{*}{$\begin{array}{l}\text { Patient } \\
\text { No. }\end{array}$} & \multicolumn{8}{|c|}{ Blood Chemistry } \\
\hline & $\begin{array}{l}\text { B. Urea } \\
(\mathrm{mg} \%) \\
(10-50)\end{array}$ & $\begin{array}{l}\text { S. Creatinine } \\
(\mathrm{mg} \%) \\
(0.5 \cdot 1.5)\end{array}$ & $\begin{array}{l}\text { S. Calcium } \\
(\mathrm{mg} \%) \\
(8.1-10.4)\end{array}$ & $\begin{array}{l}\text { S.Potassium } \\
(\mathrm{m} \mathrm{Eq} / \mathrm{L}) \\
(3.8-5.2)\end{array}$ & $\begin{array}{l}\text { Uric Acid } \\
(\mathrm{mg} \%) \\
(3.4-4.7) \\
\end{array}$ & $\begin{array}{l}\text { CPK } \\
(\mathrm{U} / \mathrm{L}) \\
(24-195)\end{array}$ & $\begin{array}{l}\text { LDH } \\
(\mathrm{mcg} \%) \\
(230 \cdot 400)\end{array}$ & $\begin{array}{l}\text { SGOT } \\
\text { (U/L0 } \\
\text { (Upto 37) }\end{array}$ \\
\hline 1 & 322 & 15.8 & 7.9 & 6.0 & 11.6 & 1322 & 1111 & 200 \\
\hline 2 & 393 & 28.7 & 7.7 & 6.7 & 12.5 & 469 & 503 & 131 \\
\hline 3 & 350 & 18.0 & 8.6 & 6.0 & 9.8 & 1028 & 1211 & 259 \\
\hline 4 & 298 & 20.7 & 10.4 & 6.1 & 13.8 & 1195 & 1321 & 220 \\
\hline 5 & 258 & 19.3 & 6.8 & 5.4 & 12.6 & 756 & 1238 & 227 \\
\hline 6 & 530 & 16.0 & 5.4 & 5.9 & 11.2 & 1235 & 1378 & 117 \\
\hline 7 & 284 & 11.7 & 6.2 & 4.5 & 12.5 & 1385 & 1440 & 180 \\
\hline 8 & 127 & 12.9 & 8.6 & 4.3 & 13.2 & 800 & 1145 & 181 \\
\hline 9 & 431 & 24.1 & 5.7 & 6.4 & 13.8 & 1136 & 1248 & 210 \\
\hline 10 & 247 & 14.6 & 6.5 & 4.5 & 9.2 & 349 & 750 & 110 \\
\hline 11 & 248 & 10.5 & 9.2 & 4.5 & 6.5 & 186 & 455 & 40 \\
\hline 12 & 240 & 6.1 & 9.8 & 3.8 & 5.0 & 340 & 944 & 32 \\
\hline
\end{tabular}

showed elevated urea and creatinine in all patients. 7(58\%) patients had hypocalcaemia, 8(66\%) were hyperurecemic and 10(83\%) had hyperkalemia. CPK and LDH were high in all cases. All the patients were subjected to haemodialysis and had 2-19 (average 7) sessions of dialysis. All but one recovered from renal failure and revealed normal renal functions in follow-up studies. The hospital stay ranged from 4-28 days.

\section{Discussion}

The pathophysiology of ARF due to traumatic rhabdomyolysis is now well recognized1,3-5,7-11,17. Briefly, extensive muscle injuiy releases large quantities of myoglobin into circulation. Since its capacity to bind serum proteins especially hepatoglobin is low ${ }^{7}$, myoglobin is freely filtered and this appears in large quantities in glomerular filtemte ${ }^{9}$. Subsequently myoglobin causes extensive obstruction and necrosis of tubules resulting in $\mathrm{ARF}^{12}$. Muscle damage alongwith elevated levels of muscle enzymes, punne metabolites, potassium and phosphorus also causes hypocalcemia in oliguric phase and hypercalcemia in about $30 \%$ of patients in recoveiy phase ${ }^{5,21}$. Several reports have shown 
ARF subsequent to trauma and rhabdomyolysis ${ }^{13,18-20}$. The causative factors of rhabdomyolysis and persuing ARF were crush injuiy and sternuous exercise ${ }^{5,12,13}$. We are reporting, trauma primarily caused by blunt injuiy inflicted by sticks, beating by leather belts, kicking and forced sternuous exercise. Our experience differs from others in the sense that majority of our patients presented late subsequent to receiving trauma. This is so because most of the patients were in a state of incarcination. Thus the classical picture of rhabdomyolysis, characterized by pain, swelling tenderness due to skeletal muscle necrosis and dark pigmented urine was not found in our cases. Nonetheless bruises and ëchymosis, flank pain, haematuria and hametamesis were significant pointers to trauma in these late presenters. Nausea and vomiting seem to be resulting subsequentto ARF especially whenone considers the hydration state of these patients, haemetamesis which is rare in such type of cases was found in $50 \%$ of these cases only on first day of beating while they were still in custody, perhaps resulted from torture. This is coroborated by the routine laboratory findings at admission, the classical brownish red urine was found in only four cases and myoglobin was detected inthree cases when two of these presented within four days. This absence of myoglobinuria is supported by earlier reports where it has been shown that myoglobinuria is an early finding or not found at all in post-traumatic rhabdomyolysis ${ }^{14-17}$. The consistentfinding mall these patients was alow urinaiy $\mathrm{pH}$, presence of occult blood in urine and microscopic heamaturia. That in all probability is related to tubular necrosis ${ }^{12}$ sub- $^{-}$ sequent to myoglobinuria. The levels of blood urea and serum creatimne in this group of patients were remarkably high when one compares these with other series of traumatic rhabdomyolysis and subsequent ARF. It is difficult to explain these levels due to late presentation alone since patient 1,2,3 and 4 though early presenters still had high levels of urea and creatinine. A question that needs to be addressed is, what is an early presentation, within hours or within days? In view of these findings we were tempted to classify all these patients as late presentors especially when one looks at the level of calcium, potassium, urea and CPK, LDH and SGOT in these groups of patients. Contrary to earlier reports of post traumatic rhabdomyolysis, where they reported CPK and LDH values of 9500-12405 and 1215-2240 respectively ${ }^{19}$, our CPK and LDH levels are much lower, while uric acid, potassium urea and creatinine are much higher, which were veiy much similar to the studies done at another centre in similar type of cases ${ }^{20}$. These all point to late presentation or aggravated ARF. Our choice of management for these patients was limited since their high uremic slates necessitated immediate dialysis. In other series several options were applied e.g., alkaline diuresis, hydration and use of other diuretics; the primary reason being early presentation within hours ${ }^{18,19}$. This paper has highlighted the abundance of a rare clinical entity inour population and the role of haemodialysis in the management of this group of patients, since all but one who died in sepsis, recovered and regained normal renal functions.

\section{References}

1. Bywaters, E.G.L. and Beall, 0. Crush injuries with impairment ofrenal function. Br. Med. J., 1941;1:427-32.

2. Cadnapaphrnchai, P., Taher, S. and Mc Donald, F.D. Acute drug associated rhabdomyolysis. Am. J. Med. Sci., 1980;280:6-10.

3. Ron, D., Taitelman, U., Michaelson, M. eta!. Prevention ofacute renal failure in traumatic rhabdornyolysis. Arch. Intern. Med., 1984; 144277-80.

4. Chugh, K.S., Singhal, P.C., Nath, I.V.S. et a!. Acute renal failure due to non-traumatic rhabdomyolysis. Postgrad. Med. J., I 979;55 :386-92.

5. Pigment nephropathy: Rhabdomyolysis and haemolysis. In the kidney and its disorders. Edited by Sweny, P., Farrington, K. and Moorthead, J.F. Oxford, London, Edinburg, Boston, Blackwell Scientific 
Publications, 1989; pp.828-41.

6. Berlin, H.S.. Simon, N.M. and Bovner, R.N. Myoglobinuria precipitated by viran infection. JAMA., 1 974;227: 1414-IS.

7. Glassock, R.J. Haematuria and pigmenturia. In textbook of nephrology. Edited by Shaul, G., Massry and Richard, 3. Glassock. 2nd edition. Baltimore, Hong Kong, London, Sydney, William and Wilkins, 1989, pp.491 -500.

8. Durbrow, A. and Flamenahaum, W. Acute renal failure associated with myoglobinuria and haemoglobinuria. In acute renal failure. Edited by Bany M. Brenner and J. Micheal Lazarus. 2nd edition. New york. Edinburg, London, Madrid, Melbourne, Tokyo. Churchill Livingstone, 1988, pp.279-93.

9. Ratcliff, P.J. Pathophysiology of acute renal failure. In Oxford textbook of clinical nephrology, Edited by Stewart Cameron, Alex, M Darison, Jean-pierre Grunfeld, David Kerr \& Eberhard Ritz, New York, Tokyo, Oxford University Press, 1992, pp.982-1 005.

10. Humphrey, MR. Pigment and crystal induced acute renal failure. In the principles and practice of nephrology. Edited by Harry, R. Jacobson, Gary E. Striker and Saulo Klahr, B.C. Philadelphia. Hamilton, Decker Inc., 1991, pp.950-59.

11. Faber, MD., Kupin, W.L., Krishna, G.G. et a!. The differential diagnosis of acute renal failure. In acute renal failure. Edited by Barry M. Brenner and J. Micheal Lazarus. 3rd edition, New York, Edinburg, London, Madrid, Mel bourne, Tokyo, Churchill Livingstone, 1993, pp.1 33-192.

12. Stevens, P.E., Pusey, C.D. and Rainford, D.J. Sprinting can seriously damage your health. Br. Med. 3., 1988;297:1518.

13. Morris, J.A., Mucha, P., Ross, S.E. et al. Acute post-traumatic renal failure. A multicenter perspective. 3. Trauma, $1991 ; 31: 1584-90$,

14. Lagarde, C., Peyronnet, P., Denis, F. etal. Salmonella bonariensis Salmonellosis, Rhabdomyolysis and acute renal failure. Nephron, 1 989;53: 179-80.

15. Gabow, PA., Kaehny, W.D., Kelleher, S.P. The spectrum of rhabdomyolysis. Medicine, 1982;61 : $141-52$.

16. Coakley, JR., Edwards, R.T.H., Mc Clelland, P. et al. Occult ischaemic necrosis of skeletal muscle associated with renal failure. Br. Med. J., 1990;301:370.

17. Haapanen, E., Partanen, J. and Pellinen, T.J. Acute renal failure following non-traumatic rhabdornyolysis. Scand. J. Urol. Nephrol., 1988;22:305-8.

18. Better, OS. and Stein, J.H. Early management ofshock and prophylaxis ofacutc renal failure in traumatic rhabdomyolysis. N. EngI. J. Med., 1990;322:825-29.

19. Shekh, IA., Shaheen, F.A.M., El-Aqeil, N.A. et al. Acute renal failure due to rhabdornyolysis following human stampede. Saudi J. Kidney Dis. Transplantation, 1994;5:17-22.

20. Shaikh, Q.A. and Naqvi, S.A.J. Exercise induced acute renal failure in 4 cases. 3. Pak. Med. Assoc., $1991 ; 4 \mathrm{I}: 314-16$.

21. Better, OS. ARF associated with rhabdomyolysis. Abstracts from XII International Congress of Ncphrology, Jerusalem, Israel. June, 13-18. 1993, p.267. 